\title{
A origem do caos - a crise de mobilidade no Rio de Janeiro e a ameaça à saúde urbana
}

\author{
The origin of chaos - the mobility crisis \\ in Rio de Janeiro and the threat to urban health
}

Renato Gama-Rosa Costa Claudia G. Thaumaturgo da Silva Simone Cynamon Cohen

\section{Resumo}

Este artigo versa sobre a mobilidade urbana e suas consequências na saúde urbana. Pretende igualmente apresentar pesquisas recentes sobre o tema e as razões históricas que transformaram o automóvel no principal meio de transporte brasileiro, ao menos para as classes mais favorecidas, em detrimento dos transportes públicos, utilizados pela grande massa de trabalhadores. 0 uso excessivo do automóvel compromete a qualidade do ar, que, somado ao estresse, à vibração e ao ruído, atinge a saúde e a qualidade de vida da população exposta aos transtornos causados pelos longos engarrafamentos. No Rio de Janeiro, esse fenômeno atinge uma etapa delicada, no momento em que se prepara para ser sede da Copa de Mundo de 2014 e as Olimpíadas de 2016.

Palavras-chave: mobilidade urbana; saúde urbana; saúde ambiental; meios de transporte; Rio de Janeiro.

\begin{abstract}
This article approaches urban mobility and its consequences to urban health. In addition, it presents recent studies about the subject and the historical reasons that have transformed the automobile into the main Brazilian means of transport, at least to the higher classes, to the detriment of public transport, used by the great mass of workers. The excessive use of automobiles affects air quality, and this, added to stress, vibration and noise, damages the health and the quality of life of the population that is exposed to the problems caused by long traffic jams. In Rio de Janeiro, this phenomenon has reached a delicate stage, in the moment that the metropolis is preparing itself to receive the 2014 World Cup and the 2016 Olympic Games.
\end{abstract}

Keywords: urban mobility; urban health; environmental health; means of transport; Rio de Janeiro. 


\section{Introdução}

A cidade do Rio de Janeiro vive, hoje, uma crise em sua mobilidade urbana, que representa uma ampla ameaça à saúde e à qualidade de vida de seus habitantes. 0 uso excessivo de automóveis e demais veículos automotores, movidos, em sua maioria, a combustíveis fósseis, comprometem a qualidade do ar urbano com emissões de gases e material particulado na atmosfera. Tais efeitos, somados aos relativos ao estresse, à vibração e ao ruído, atingem a saúde e a qualidade de vida da população, sobretudo da parcela mais exposta aos transtornos causados pelos longos e, cada vez mais frequentes engarrafamentos.

Este artigo coloca em debate a mobilidade urbana e suas consequências na saúde urbana. Pretende igualmente apresentar pesquisas recentes sobre o tema e as razões históricas que transformaram o automóvel no principal meio de transporte brasileiro, ao menos para as classes mais favorecidas, em detrimento dos transportes públicos, utilizados pela grande massa de trabalhadores, que vivem uma crise proporcionada pela falta de recursos em conservação e investimentos. No Rio de Janeiro, esse fenômeno atinge uma etapa delicada, no momento em que a cidade se prepara para ser sede da Copa de Mundo de Futebol, em 2014, e das Olimpíadas em 2016. Quais são as implicações do processo do crescimento urbano sobre a saúde?

À luz das conquistas da nova história, a identificação dos atores e instituições que participaram do processo de circulação dentro e fora das cidades, durante a primeira metade do século XX, nos parece desejável. Não queremos com isso isolar determinada categoria, uma vez que os próprios atores participavam indistintamente de uma e de outra. Pode-se dizer que, independentemente do grupo de atores envolvidos, os discursos para a implementação de um projeto nacional visando à abertura de rodovias tiveram sempre um cunho progressista, confiando ao automóvel o papel de integrador e de portador do progresso à nação, iniciado com a chegada dos primeiros veículos automotores ao Brasil. Ao longo do século XX, essa confiança nos automóveis levou a um lento e gradual desmantelamento da malha ferroviária. Hoje, as cidades brasileiras dependem basicamente das rodovias como vias de transporte nacional e urbano. A cidade do Rio de Janeiro não é diferente, possuindo um sistema de trens urbanos e metropolitanos muito aquém de suas necessidades. Parece-nos, de fato, extremamente relevante entender assim as razões históricas e os grupos sociais que fizeram dos veículos sobre rodas o principal meio de locomoção brasileiro.

Identificamos duas categorias profissionais de relevância para as questões propostas: os políticos, aqui representados pelos administradores e a ação dos órgãos públicos, e os técnicos, abrangendo os engenheiros e urbanistas. De forma similar, a identificação desses grupos foi objeto de textos de Dinhobl (2003), Flonneau (2003a e 2003b), Barles e Guillerme (2003), reconhecendo, nos engenheiros e sanitaristas, primeiramente, e depois nas autoridades públicas e nos arquitetos e urbanistas, as categorias profissionais a se preocuparem com as questões do tráfego urbano, decorrente às vezes do processo de industrialização, mas inquestionavelmente impulsionado pela revolução tecnológica e industrial na Europa e nos Estados Unidos. 


\section{Automóvel: o mal necessário de nossas cidades}

Estudos sobre o automóvel e a cidade costumam identificar alguns períodos comuns sobre a evolução desse transporte no meio urbano. Essa periodização foi levantada por MacShane (1984) e por Barles e Guillerme (2003). 0 primeiro autor separa em quatro etapas a presença do automóvel nas cidades norte-americanas, que se inicia em 1894, ano do surgimento do primeiro veículo com motor à explosão nos Estados Unidos, e vai até 1905-1906. Nesse primeiro momento, o automóvel aparecia como uma curiosidade tecnológica reservada às classes mais abastadas, e o poder público, salvo leis pontuais de limitação de velocidade e de algumas instruções de segurança, não demonstrava estar muito atento a uma nova realidade que se colocava.

0 segundo período, entre esses anos e 1914, está identificado com a fabricação em série de automóveis, desenvolvida por Henry Ford, que vai acarretar de imediato o progressivo barateamento do preço dos veículos e ajudá-lo a se tornar mais popular, embora ainda ligado ao lazer urbano. Em consequência, surgem os primeiros engarrafamentos nas cidades, o que, por sua vez, desencadeia uma série de legislações urbanas específicas para o automóvel na cidade.

0 terceiro período está delimitado pelos anos de 1914 e 1923, quando se torna fato a presença do automóvel na cidade e este passa a ser o principal meio de transporte urbano nas cidades norte-americanas. Finalmente, os anos de 1923 a 1940 delimitam o último período, onde se tem o início da lenta desativação, em nível mundial, dos bondes elétricos. Esse período é igualmente marcado pelos constantes engarrafamentos urbanos e pelo início, já nessa época, dos consequentes estudos sobre os efeitos desastrosos do automóvel para as cidades.

Barles e Guillerme (2003) separam a periodização em quatro momentos e confirmam alguns períodos adotados por MacShane. 0 primeiro período estudado pelos pesquisadores franceses estaria relacionado à evolução do transporte urbano como um todo, iniciando por volta de 1820/1830 -, e que corresponderia às primeiras ações em relação à pavimentação e a calçamentos, ao aparecimento dos ônibus e bondes puxados à tração animal, das bicicletas, etc. Em Paris,os autores destacam que esse período estaria especialmente identificado à atuação dos engenheiros da École des Ponts et Chausées, iniciada ainda no século XVIII.

0 segundo momento estaria associado aos anos de pioneirismo do automobilismo, ao surgimento das primeiras leis de trânsito e a uma competição econômica entre as rodovias e as ferrovias. Esse período inicial para a história do automóvel moderno vai do ano do seu surgimento, que varia de país para país, mas que se situa entre 1897 e 1900, indo até as primeiras duas décadas do século XX.

Por volta dos anos 1880, a questão das diferenças entre os tipos de vias locais já ga- nhara a atenção de diferentes atores no cam- po técnico, seja pelas razões de circulação, higiene e embelezamento ou pela própria di- versidade crescente dos meios de transporte e locomoção. Soria y Mata, para sua Ciudad Lineal (1882/1913), previu um grande eixo, com larguras de quarenta, sessenta ou cem metros. Essa grande rua, plantada com quatro, seis, oito ou mais fileiras de árvores, teria 
espaços separados para automóveis, bicicletas, veículos de tração animal, bondes elétricos e pedestres. Os comprimentos dessas vias não foram definidos a priori, mas, para romper a uniformidade, de tempos em tempos, Soria y Mata $(1882 / 1913$, p. 12) previu que fossem

[...] colocadas praças espaçosas e graciosas - circulares, elípticas ou poligonais ornadas com fontes decorativas e floridas, monumentos comemorativos como esculturas, obeliscos, etc.

A cada trezentos metros, deveriam também ser instaladas o que o engenheiro chamava de estações de conforto, ou seja, quiosques com banheiros, postos de polícia, cabines telefônicas, painéis de avisos, um ponto de espera do bonde, etc. (ibid.).

Uma análise da Enciclopédia de Higiene e de Medicina Pública (1897) nos assinala ou- tras pistas a serem exploradas, nesse período de inovações e hesitações quanto às especi- ficidades que deveriam designar as vias, suas dimensões (largura e comprimento), seus tra- çados, suas funções, em suma. No segundo capítulo da parte dedicada à higiene urbana, grandes vias deveriam ser genericamente de- nominadas artérias, ou seja, um meio de cir- culação que precisaria ser mantido cômodo e seguro, e deveriam expressar as reservas de ar saudável das cidades e a oferta aos habitantes de locais para passeios agradáveis e para a prática de exercícios.

No início do novo século, o francês Eugène Hénard (1849-1923) se preocuparia com o tráfego da cidade de Paris, pois acreditava que, em poucos anos, se nada fosse feito, a questão poderia acarretar as maiores dificuldades da vida nas grandes metrópoles. $\mathrm{Na}$ verdade, a circulação nas cidades, para Hénard, articulava-se com a "canalização" de todo o tipo de elemento associado a uma cidade sadia e moderna, desde o ar puro e a água potável, até os meios de comunicação, como o telégrafo e o telefone. Essas associações desenvolvidas por Hénard nos levam a perceber que, nesse momento, as vias urbanas, ruas e avenidas ainda estão vinculadas a um pensamento higienista e sem uma nomenclatura definida.

A partir de uma visão cientificista e classificatória, Hénard divide as ruas em seis categorias: doméstica, profissional, econômica, mundana, ferial e popular. Os dois tipos de circulação que mais preocupavam o urbanista francês eram a "econômica" e a "mundana", por constituírem a essência da vida das cidades e por provocarem os maiores movimentos de veículos. Hénard considerava ainda que estes tipos de circulação seriam mais fortemente transformados pelo progresso do ciclismo e do automobilismo e iriam, em breve, subverter a disposição das vias públicas, provocando a criação de novas avenidas, associadas à velocidade dos novos meios de transporte (Hénard, 1982/1909, p. 186). Nesse sentido, o automóvel aparecia em seu estudo como o único meio de locomoção capaz de assegurar a plena circulação de uma grande capital.

Nos Estados Unidos, a preocupação e tematização das vias públicas locais parecem ter surgido também em meados do século XIX, com os projetos do paisagista Frederick Law Olmsted, cuja primeira obra foi para o Central Park, em 1857. Olmsted acreditava na importância dos parques públicos para a saúde e para a recreação, e buscou preservar o caráter bucólico do Central Park, impedindo a abertura de suas avenidas para o transporte público, favorecendo o acesso rápido e livre do 
transporte individual. Logo, outras vias iguais a essa seriam abertas. Nascia, assim, a ideia de parkway, um tipo de via na qual as ideias de recuperação de uma natureza selvagem e ou da experiência de um refúgio romântico se opunham a formas, às vezes consideradas "cruéis", de desenvolvimento urbano (Dupuy, 1991, p. 123).

0 terceiro período das relações entre 0 automóvel e a cidade, segundo Barles e Guillerme (2003), está balizado entre a Primeira e a Segunda Guerra Mundial, mais precisamente entre 1920 e 1939, e corresponderia ao momento de consolidação das indústrias automobilísticas, sobretudo nos Estados Unidos, e do desenvolvimento dos planos de remodelação urbana encomendados pelos poderes públicos, onde aparecem em destaque as questões relacionadas à circulação viária nas cidades. Nesse período, dar-se-ia igualmente a vitória do automóvel e do ônibus sobre os trens e os bondes. 0 último período englobaria o fim da Segunda Guerra até os dias de hoje, mostrando que o automóvel particular é o meio de transporte urbano por excelência e um mal necessário para nossas cidades.

Entre 1922 e 1925, é possível verificar como o tema do automóvel havia conseguido adeptos, também em outras fontes de época. De fato, nas manchetes dos jornais parisienses do ano de 1923, separadas por Le Corbusier e publicadas em seu livro Urbanismo, grande parte é dedicada ao tema da circulação automobilística. Artigos de jornais, como "Aprendamos a circular", "Os veículos no teto", "0 Urbanismo", "Para evitar o congestionamento", "m cavalo para mil cavalos-vapor", transcritas justamente dentro do subcapítulo A Circulação, mostram não apenas as novas preocupações do arquiteto franco-suíço, mas também como o tema havia se popularizado entre 1909, data da divulgação das ideias de Hénard, e 1925 - ano da publicação de Urbanismo, isto é, em apenas 15 anos (Le Corbusier, 2000, p. 118).

A partir de 1920, já não são apenas esportistas ou fabricantes que se sentem interessados pelo automobilismo e pelo o que 0 automóvel trazia com ele. A velocidade e a mobilidade agora resumiam o próprio progresso alcançado pela sociedade moderna. Para muitos urbanistas, a partir de então, a velocidade seria um dos temas recorrentes em seus discursos. Le Corbusier, por exemplo, sugeria que se interditasse a circulação das viaturas a cavalo e de baixa velocidade nas vias principais; que se separasse as demais vias entre circulação rápida e lenta; que se adotasse o sentido de mão única para determinadas vias; que se regulasse o estacionamento; e que se retirasse os bondes do centro de Paris. Num crescendo, ele chegaria a afirmar que: "A cidade que dispõe da velocidade dispõe do sucesso" (ibid., p. 180).

Pode-se dizer que nesses anos são lançadas as bases do urbanismo moderno que seguiriam quatro postulados básicos, já anunciados em congresso realizado em Estrasburgo no ano de 1923, o Congrés International de I'Urbanisme et Higièn e Municipale. Le Corbusier resumiria esses postulados em seu livro:

Descongestionar o centro das cidades para fazer frente às exigências do trânsito; aumentar a densidade do centro das cidades para realizar o contato exigido dos negócios; aumentar os meios de circulação, ou seja, modificar completamente a concepção atual de rua, que se acha sem 
efeito ante o fenômeno novo dos meios de transporte modernos: metrôs ou carros, bondes, aviões; aumentar as superfícies arborizadas, único meio de assegurar a higiene suficiente e a calma útil ao trabalho atento exigido pelo ritmo novo dos negócios. (lbid., p. 91)

Percebemos o quão problemático estão nossas cidades hoje que enfrentam retenções quilométricas nos tráfegos urbanos e o quanto ficou distante esse ideal proposto por Corbusier, há noventa anos. A velocidade de nossos automóveis está mais próxima das mulas, animal tão execrado por Corbusier, por associá-lo à uma época pouco civilizada de nossas sociedades modernas.

\section{Antecedentes do caso brasileiro}

De forma semelhante, Benetti (1997) identifica uma cronologia relacionada às avenidas brasileiras, separando os períodos de 1830 a 1906, de 1906 a 1926, de 1926 a 1940, de 1940 a 1969 e, finalmente, de 1969 a 1999. Grosso modo, o primeiro momento, de acordo com o próprio autor, estaria ligado às questões tratadas pelo higienismo em relação às vias públicas; o segundo teria nas cidades de Paris e Viena fontes de inspiração para a realização de planos urbanos; o terceiro estaria associado às ideias e aos estudos da Société Française des Urbanistes; o quarto, às recomendações do Congresso Internacional de Arquitetura Moderna (CIAM), aos estudos de Le Corbusier e à construção de Brasília; e o último, ao contextualismo.
Nosso estudo escolheu alguns anos como os momentos chave do arco temporal adotado, por entender serem eles marcos importantes para o desenvolvimento das questões propostas.

Seriam eles os anos de 1906-1907, 19261927, 1937-1939, 1945-1947 e 1954, que definem, assim, períodos de continuidade entre momentos de ruptura.

0 ano de 1906 marca o final da gestão de Francisco Pereira Passos na prefeitura da cidade do Rio de Janeiro. Sua administração e o decisivo conjunto de iniciativas do governo federal implementaram obras que dariam à capital do país diretrizes para a formação da infraestrutura urbana, sobretudo viária, a qual ainda permanece até os dias de hoje. Nesse mesmo ano, foi pensada pelo Barão do Rio Branco a primeira viagem com o uso do automóvel entre o Rio e Petrópolis com o intuito de hospedar autoridades em visita à capital brasileira por ocasião da exposição internacional de 1908.

0 ano de 1906 marca, assim, o início das questões em torno tanto da melhoria da circulação interna da cidade, a partir das primeiras leis de tráfego urbano, quanto da abertura de rodovias. Em 1907, o fato de a capital federal possuir 35 automóveis motivou a criação da instituição associada ao desenvolvimento do rodoviarismo brasileiro: o Automóvel Club do Brasil. Ele seria o responsável pela organização dos primeiros congressos brasileiros de estradas de rodagem, iniciados em 1916, onde se discutiram, entre outras coisas, a abertura de um caminho rodoviário para Petrópolis. Esse primeiro marco temporal nos revela, então, como essas questões apareceram nos projetos dos urbanistas da época, inclusive 
nos de Pereira Passos. Esse engenheiro havia trabalhado na Comissão de Melhoramentos da Cidade de Rio de Janeiro, em 1875, quando a organização de um plano geral de alargamento e retificação de vias com fins higienistas caminhava ao lado das propostas de embelezamento da cidade. Essas questões, sem dúvida, seriam retomadas nas obras por ele realizadas entre 1903 e 1906, revelando esse compromisso higienista.

De 1925 a 1940 é o período em que o automóvel se revela o meio de transporte urbano por excelência para os norte-americanos, ao mesmo tempo que as avenidas se desenvolvem para se tornarem as primeiras autoestradas urbanas modernas. Coincide, assim, com a época das importantes vias de penetração nos centros das cidades, justamente o período em que se estudam, no Brasil, as novas Rio-Petrópolis e Rio-São Paulo. Até 1940, tem-se o sucesso das autoestradas americanas, desencadeando projetos específicos para essa nova rede viária e os parkways, que no Rio de Janeiro daria origem às vias do Parque do Flamengo e à do Rio Faria-Timbó (não construída).

Em 1926, se inicia o governo de Washington Luís na presidência da República, último governo da chamada República Velha. Sua presidência coroaria uma sólida carreira política baseada no rodoviarismo, iniciada ainda em 1908, como secretário de Justiça e Segurança Pública do Estado de São Paulo. Washington Luís desenvolveria sua ascensão política assumindo mandatos sucessivos de deputado estadual, prefeito e governador de São Paulo, ao mesmo tempo que participava da diretoria do Automóvel Club do Brasil. Os anos de 1926 e 1927 marcam o início dos projetos e das obras da Rio-Petrópolis, inaugurada em 1928; do projeto de urbanização do Bairro Industrial de Manguinhos; do Plano de Remodelação, Extensão e Embelezamento para a cidade do Rio de Janeiro, a cargo de Agache; da criação do Club dos Bandeirantes - clube ligado às questões de integração do território nacional, inclusive fazendo uso das rodovias; da criação da Diretoria de Estradas de Rodagem de São Paulo, primeiro órgão rodoviário brasileiro; e da criação, pelo governo federal, da Comissão de Estradas de Rodagem Federal, cujo primeiro trabalho foi justamente abrir a Rio-Petrópolis.

Em 1937, tem início o Estado Novo, com Getúlio argas, que havia sido ministro de Washington Luís. Vargas vai continuar, e mesmo incrementar, os projetos rodoviaristas iniciados por seu antecessor. Ainda em 1937, inicia-se igualmente a gestão de Henrique Dodsworth na prefeitura do Rio de Janeiro. Tal ano marca, ainda, o ano da criação do DNER, órgão responsável direto pelo controle e desenvolvimento das obras de aberturas de estradas brasileiras, e, no ano de 1939, as obras da variante Rio-Petrópolis, futura avenida Brasil, têm início.

Em 1945, ocorre o fim do Estado Novo e o início do período da redemocratização brasileira. Nesse ano, o DNER tem sua estrutura interna reorganizada pelo Decreto-lei n. 8.463, dando origem ao Fundo Rodoviário Nacional. Em 1947, tem-se a inauguração do último tre- cho da já denominada Avenida Brasil, no go- verno de Eurico Gaspar Dutra, justamente o correspondente à região de Manguinhos. Três anos depois, o mesmo Dutra inicia as obras de sua duplicação. 0 ano de 1954 é marcado pelo suicídio de Getúlio Vargas e representa o início de um período conturbado, onde em menos de um ano e três meses, três presidentes assumem 
a República brasileira, até a eleição que dá posse a Juscelino Kubitschek, cujo governo está associado à consolidação das ações rodoviaristas e à montagem do parque automobilístico brasileiro, com a Ford e a Volkswagen, que, em 1953, já haviam inaugurado fábricas em território brasileiro.

Todos esses eventos convergentes fazem desses anos um momento de acirramento dos debates sobre a forma e a expansão da cidade, ocorridos par e passo com o desenvolvimento do rodoviarismo, culminando em uma nova representação de cidade associada ao automóvel, sem perceber o quanto essa associação poderia, um dia, ser tão prejudicial à saúde humana e ambiental.

\section{A mobilidade urbana: a situação atual}

Da década de 1950 em diante, há uma forte predominância do transporte sobre rodas (automóveis e ônibus) e um lento desmantelamento da malha ferroviária. Kleiman (1994) reconhece o grande investimento em redes viárias, feito a partir dos anos 1950, e considera os períodos anteriores como intro- dutórios desse processo. Ele baseia suas aná- lises em dados estatísticos, incluindo os inves- timentos em redes de infraestrutura urbana, realizados no período que vai de 1938 a 1998 . 0 privilégio da rede viária, no seu entender, dava-se por ser mais visível à população, cor- respondendo meIhor aos interesses políticos.

Tais investimentos ocasionaram uma predominância do meio de transporte sobre rodas em relação aos demais. Segundo o IPEA (2011), nas grandes cidades os meios de transportes mais utilizados são o ônibus (44\%), 0 carro $(23,8 \%)$, a moto $(12,6 \%)$ ou mesmo a pé $(12,3 \%)$. Os resultados são apresentados como média nacional e é feita a divisão entre as cinco regiões, detalhados na Tabela 1.

Ao aprofundar a análise por região, percebe-se que na região Nordeste, por exemplo, o uso de motos equivale a $19,4 \%$, e o transporte a pé a $18,8 \%$. Apenas $13 \%$ usam o carro para locomoção na cidade. No Centro-Oeste, o uso de carro é o maior das cinco regiões, com $36,5 \%$ da população utilizando esse meio de transporte e apenas $6,5 \%$, utilizando moto. Também são apresentados dados cruzando o tipo de transporte e o nível de escolaridade, conforme mostrado no Tabela 2.

Tabela 1 - Meio de transporte por região (\%)

\begin{tabular}{l|c|c|c|c|c|c}
\hline & Brasil & Sul & Sudeste & Centro-Oeste & Nordeste & Norte \\
\hline Transporte público (ônibus) & 44,3 & 46,3 & 50,7 & 39,6 & 37,5 & 40,3 \\
Carro & 23,8 & 31,7 & 25,6 & 36,5 & 13,0 & 17,6 \\
Moto & 12,6 & 12,4 & 11,6 & 6,5 & 19,4 & 8,2 \\
A pé & 12,3 & 7,6 & 8,3 & 13,7 & 18,8 & 16,1 \\
Bicicleta & 7,0 & 2,0 & 3,8 & 3,7 & 11,3 & 17,9 \\
\hline
\end{tabular}

Fonte: Ipea-Sips (2011). 
Tabela 2 - Tipo de transporte e nível de escolaridade (\%)

\begin{tabular}{|c|c|c|c|c|}
\hline Transporte & $\begin{array}{l}\text { Até } 4^{\mathrm{a}} \text { série } \\
\text { do } 1^{\circ} \mathrm{grau}\end{array}$ & $\begin{array}{l}5^{\mathrm{a}} \text { a } 8^{\mathrm{a}} \text { série } \\
\text { do } 1^{\circ} \text { grau }\end{array}$ & $\begin{array}{c}2^{\circ} \text { grau completo } \\
\text { ou incompleto }\end{array}$ & $\begin{array}{c}\text { Superior incompleto, } \\
\text { completo e pós-graduação }\end{array}$ \\
\hline Bicicleta & 9,1 & 9,3 & 5,8 & 0,5 \\
\hline A pé & 6,7 & 14,3 & 16,4 & 11,8 \\
\hline Moto & 20,7 & 10,9 & 8,9 & 5,9 \\
\hline Carro & 13,6 & 18,6 & 25,9 & 52,4 \\
\hline Transporte público & 49,9 & 46,9 & 43,0 & 29,4 \\
\hline
\end{tabular}

Fonte: Ipea-Sips (2011).

Pela Tabela 2 pode-se observar que $52,4 \%$ da população com nível superior completo ou incompleto e com pós-graduação utilizam carro e $29,4 \%$ utilizam o transporte público. Para as pessoas com escolaridade a partir da $4^{\mathrm{a}}$ série até o segundo grau, o uso majoritário é o público (entre $43 \%$ e $49,9 \%$ ), enquanto que apenas $13,6 \%$ utilizam o automóvel.

Outro fator levantado na pesquisa do Ipea, e que nos interessa analisar é em relação à integração utilizada pelo cidadão no dia a dia (Tabela 3).

Tabela 3 - Tipo de integração utilizada no dia-a-dia (\%)

\begin{tabular}{l|c|c|c|c|c|c}
\hline & Brasil & Sul & Sudeste & Centro-Oeste & Nordeste & Norte \\
\hline Não existe em minha cidade & 26,3 & 33,7 & 19,0 & 21,3 & 23,3 & 55,6 \\
Não usa, apesar de existir & 27,5 & 14,7 & 37,0 & 17,3 & 24,5 & 22,0 \\
Ônibus-ônibus & 33,2 & 42,6 & 25,2 & 32,3 & 49,8 & 21,1 \\
Ônibus-metrô & 4,9 & 4,2 & 9,2 & 0,8 & 0,8 & 0,8 \\
Ônibus-trem & 1,1 & 0,5 & 2,4 & 0,0 & 0,0 & 0,0 \\
Trem-metrô & 0,9 & 0,0 & 1,9 & 0,8 & 0,0 & 0,0 \\
Outro tipo & 0,8 & 0,0 & 1,3 & 2,4 & 0,0 & 0,0 \\
Não sabem & 0,7 & 0,0 & 0,9 & 2,4 & 0,4 & 0,0 \\
Não responderam & 4,5 & 4,2 & 3,0 & 22,8 & 1,2 & 0,0 \\
\hline
\end{tabular}

Fonte: Sips (2010). 
Na Tabela 3 foi observado que $55 \%$ dos entrevistados da região Norte alegaram que não há integração na cidade que residem. $\mathrm{Na}$ região Sudeste, $37 \%$ dos entrevistados revelou não usar o serviço de integração, mesmo com sua existência. A região Sul aparece com o menor percentual, 14,7\%. Entre os tipos de integração mais utilizados, o primeiro é o ônibus-ônibus, com uma média nacional de 33,2\%, e com as regiões Nordeste e Sul como as que mais utilizam - 49,8\% e 42,6\%, respectivamente. A região Sudeste é a que mais utiliza o ônibus juntamente com outro tipo de integração, 0 metrô, com quase $10 \%$ dos casos. A integração entre ônibus e trem é quase inexistente em todas as regiões, como podemos observar, o que confirma a preferência pelo transporte sobre rodas e com motor a combustão, mais poluente.

0 motivo do deslocamento também foi pesquisado, conforme a Tabela 4, confirmando que o maior motivo de deslocamento para $72,2 \%$ das pessoas com ensino superior incompleto, completo ou pós-graduação ainda é o trabalho.

As características de um bom transporte estão detalhadas na Tabela 5 .

Tabela 4 - Razão para a maioria dos deslocamentos dentro de sua cidade segundo a escolaridade (\%)

\begin{tabular}{l|c|c|c|c|c}
\hline \multicolumn{1}{c|}{ Escolaridade/Motivo } & Trabalho & Educação & Saúde & Lazer & NS/NR \\
\hline Até 4 ${ }^{\mathrm{a}}$ série do primeiro Grau & 51.1 & 1.7 & 23.3 & 20.0 & 4.0 \\
De 5 ${ }^{\mathrm{a}}$ a 8 ${ }^{\mathrm{a}}$ série do primeiro Grau & 64.0 & 2.3 & 8.2 & 17.6 & 4.9 \\
Segundo Grau completo ou incompleto & 69.3 & 6.2 & 4.1 & 17.3 & 3.1 \\
$\begin{array}{l}\text { Ensino superior incompleto } \\
\text { ou completo ou pós-graduação }\end{array}$ & 72.2 & 10.7 & 2.9 & 10.4 & 3.7 \\
\hline
\end{tabular}

Fonte: Ipea-Sips (2011). 
Tabela 5 - Quais as características para um bom transporte

\begin{tabular}{|c|c|c|c|c|c|c|}
\hline Motivos & Brasil & Sul & Sudeste & Centro-Oeste & Nordeste & Norte \\
\hline Ter disponível mais de uma forma de se deslocar & 13.5 & 18.3 & 18.1 & 7.2 & 10.2 & 5.8 \\
\hline Ser rápido & 35.1 & 31.2 & 36.9 & 36.8 & 38.5 & 25.5 \\
\hline Sair num horário adequado à sua necessidade & 9.3 & 11.5 & 8.0 & 7.2 & 10.8 & 9.4 \\
\hline Chegar no horário desejado a seu destino & 4.8 & 5.6 & 5.3 & 2.8 & 5.5 & 2.7 \\
\hline Ser saudável & 1.3 & 0.5 & 0.9 & 1.3 & 2.1 & 1.8 \\
\hline Poluir pouco & 2.3 & 0.7 & 2.1 & 1.3 & 3.6 & 3.3 \\
\hline Ser barato & 9.9 & 8.5 & 8.6 & 13.4 & 10.7 & 11.2 \\
\hline Ser confortável & 9.7 & 7.8 & 7.6 & 10.6 & 10.5 & 16.4 \\
\hline Ter menor risco de assalto & 2.3 & 1.5 & 1.3 & 2.5 & 1.9 & 7.0 \\
\hline Ser fácil de usar & 1.2 & 1.5 & 0.7 & 0.9 & 1.5 & 2.4 \\
\hline Ter menor risco de acidente & 4.2 & 4.4 & 4.2 & 5.3 & 2.7 & 6.4 \\
\hline Cobrir uma área maior & 2.6 & 3.9 & 1.1 & 5.9 & 1.0 & 5.2 \\
\hline Ser cômodo & 1.4 & 2.0 & 2.1 & 1.6 & 0.3 & 0.9 \\
\hline Outra característica & 1.4 & 1.7 & 2.0 & 0.3 & 0.7 & 1.2 \\
\hline NS & 0.4 & 0.2 & 0.7 & 0.9 & 0.0 & 0.0 \\
\hline NR & 0.7 & 0.7 & 0.5 & 2.2 & 0.0 & 0.0 \\
\hline
\end{tabular}

Fonte: Ipea-Sips (2011).

0 anseio pela rapidez dos transportes lidera em nível nacional e em todas as grandes regiões, com uma média de 30\%. Afinal, a máxima preconizada por Corbusier em 1925, "a cidade que dispõe da velocidade dispõe do sucesso" (Le Corbusier, 2000, p. 167) ainda é o que se busca nas grandes cidades. Em segundo lugar, de acordo com a tabela acima, vem a possibilidade de se deslocar com outros meios, evidenciando, talvez, que o sistema rodoviário apresenta sinais de esgotamento. Outros relevantes são: o preço, por ser mais barato; a comodidade para quem o utiliza; a disponibilidade em horário adequado à saída. Poucos entrevistados se preocupam com a questão da saúde. Mas, a segurança apareceu como item importante na Tabela 6. 
Tabela 6 - Sensação de segurança no meio de transporte mais utilizado

\begin{tabular}{l|c|c|c|c|c|c}
\hline & Brasil & Sul & Sudeste & Centro-Oeste & Nordeste & Norte \\
\hline Sim, sempre & 40.0 & 44.9 & 40.0 & 43.9 & 36.3 & 37.3 \\
Na maioria das vezes & 26.9 & 43.2 & 26.8 & 24.0 & 23.1 & 17.6 \\
Raramente & 13.6 & 4.6 & 13.8 & 18.1 & 12.4 & 22.4 \\
Não, nunca & 19.0 & 6.8 & 19.1 & 12.5 & 28.0 & 22.1 \\
NS & 0.1 & 0.0 & 0.2 & 0.6 & 0.0 & 0.0 \\
NR & 0.4 & 0.5 & 0.2 & 0.9 & 0.2 & 0.6 \\
\hline
\end{tabular}

Fonte: Ipea-Sips (2011).

Pelo que foi visto nas tabelas acima, se- gundo o estudo realizado pelo IPEA, por meio do Sistema de Indicadores de Percepção Social, para a identificação da percepção da população sobre mobilidade urbana, mostra-se a heterogeneidade física-geográfica, socioeconômica e cultural, presentes nas regiões brasileiras. Existem problemas relacionados à infraestrutura urbana e qualidade dos transportes públicos. As diferenças mais significativas são apontadas quando há o cruzamento de dados sobre transportes e níveis de renda e escolaridade. Por fim, a integração de transporte público mais utilizada é o ônibus/ônibus.

Portanto, há necessidade do governo em promover novas modalidades de transporte, em substituição aos automóveis e ônibus, para que possa diminuir o fluxo de veículos e a emissão de gases poluentes na atmosfera, beneficiando a saúde pública.

\section{A mobilidade e a saúde urbana}

Por décadas, os padrões do higienismo na produção e promoção de ambientes urbanos salubres são refletidos e debatidos. No campo da saúde coletiva são debatidos os significados das políticas públicas na área da saúde, focando no indivíduo, mas também abarcando a complexa rede externa e interna que influencia o estado de saúde. Esse debate ocorre nos eixos da "Promoção da Saúde", da "Qualidade de Vida" e dos "Determinantes Sociais da Saúde", como também por meio das noções de sustentabilidade e de vulnerabilidade. A partir desse contexto, discute-se a problemática do urbano, tendo em vista a construção de cidades como espaços mais saudáveis (Buss e Pellegrini, 2007). 
Ressalta-se na investigação das políticas públicas na área da saúde urbana a infraestrutura urbana e seus serviços como indutores da saúde da população. Considera-se ainda o estilo de vida, o trabalho e a renda, o lazer, a habitação, a alimentação e nutrição, a participação e mobilização da população, o transporte, dentre outros, como importantes vetores de saúde e/ou da qualidade de vida.

Segundo a Opas (2007), a articulação saúde-cidade envolve o aprofundamento de conceitos como urbano, urbanidade, urbanização, que são capazes de moldar os níveis de saúde da população e auxiliam na interpretação de especificidades analíticas e práticas da saúde urbana. Como também, numa perspectiva geográfica, a definição do território, o modo de ocupação e mobilidade urbana prescreve a dinâmica social. Assim, a urbanidade é a qualidade de ser urbano. $E$, a urbanização é a transformação do espaço quanto ao tamanho, densidade e heterogeneidade das cidades.

0 urbano é um fenômeno social complexo que produz particularidades no modo de viver e de pensar (Wirth, 1987, p. 92). E, para o aprofundamento do entendimento sobre sua morfologia, torna-se imprescindível a visão das multidimensões que o forma, sobretudo, a análise das relações sociais que se dão e que implicam em demandas específicas.

Caiaffa et al. (2008), em uma visão longitudinal, interpretam o fenômeno da urbanização como um complexo, onde a cidade cresce (ou diminui), modifica e influencia a saúde da população. A urbanidade, em visão transversal, é, para esses autores, a imagem qualitativa da urbanização que pode ser definida como o impacto desse processo para a população que vive nas cidades em determinado momento.
Seguindo essa visão, o conceito de saúde urbana pode ser sistematizado em três pontos: (a) a urbanização, que é esperado pro- duzir somente efeitos benéficos - conhecidos como "vantagens urbanas"- pode acarretar danos sociais, econômicos e ambientais de grande impacto, difíceis de mensurar; (b) os atributos físicos e sociais (contexto) da cidade e seus bairros e/ou vizinhanças podem afetar a saúde dos indivíduos; (c) a ocorrência dos eventos relacionados à saúde, associadas a atributos dos indivíduos no "lugar urbano", assim como o somatório das propriedades do agregrado desses indivíduos, indo além de seus atributos individuais.

A Opas (2007) destaca que a urbanidade faz nascer agravamentos devido às doenças a ela relacionadas, como a poluição do ar, causada por veículos automotores e pelas indústrias, que resultam em altas taxas de internação hospitalar de pacientes acometidos com doenças respiratórias. Para tanto, define para fins metodológicos e de intervenção, a saúde urbana entendida como o ramo da saúde pública que estuda os fatores de riscos das cidades, seus efeitos sobre a saúde e as relações sociais urbanas. As cidades passam a ser entendidas como metabolismos complexos com redes e conexões que se estendem globalmente, com relevantes implicações na saúde, como as decorrentes da poluição do ar e sonora; de acidentes de trânsito; da segurança pública; da crise da mobilidade e consequente desagregação social; da perda de identidade cultural, dentre outras.

A saúde urbana, como fator instrumental do desenvolvimento humano sustentável, busca intervir no espaço das políticas e práticas públicas de forma integradora, com o intuito de alcançar medidas que possibilitem a todos os 
cidadãos desenvolver em sua plenitude, suas capacidades, crenças e desejos (Opas, 2007).

\section{A ameça à saúde e à saúde ambiental}

0 consumo de combustíveis fósseis é hoje cerca de 30 vezes maior do que em 1900, uma vez que grande parte desse aumento se deu a partir de 1950, com o incremento do processo de urbanização (Brandão, 2001). E hoje, cerca de meio século após a implementação das ações rodoviaristas consolidadas por Juscelino Kubitschek, a questão da mobilidade urbana, nos grandes centros urbanos do país, adotou rumos não previstos naquela ocasião. A abertura de novas vias, considerada então uma solução desenvolvimentista, contribuiu diretamente para o crescimento da frota veicular e demonstra hoje não só não ter garantido conforto para a população, como também ter contribuído para a origem do caos atual, que é o trânsito de veículos automotores nas grandes cidades do país.

A emissão de gases tóxicos por veículos automotores contribui para a deteriorização da qualidade do ar nos centros urbanos e produz efeitos adversos na saúde de seus habitantes. Gases como o monóxido e o dióxido de carbono, óxidos de nitrogênio e de enxofre, hidrocarbonetos, assim como os materiais particulados emitidos pelos combustíveis fósseis, estão associados a milhões de casos de doenças respiratórias nas grandes cidades e são responsáveis por milhares de mortes prematuras a cada ano (World Bank, 2000).

0 setor de transportes rodoviários, além dos danos à saúde da população, também é responsável pela emissão de gases do efeito estufa - GEE. Segundo o Inventário e Cenário de Emissões dos Gases do Efeito Estufa na Cidade do Rio de Janeiro, produzido pelo Centro Clima/ Coppe/UFRJ (Centro Clima, 2011), o setor de transportes de modo geral foi responsável por $66 \%$ das emissões desses gases na cidade do Rio de Janeiro, no ano de 2010. E, dentro desse setor, os transportes rodoviários foram responsáveis por cerca de $80 \%$ dessas emissões.

Segundo Cançado et al. (2006), os efeitos agudos da poluição do ar sobre doenças respiratórias afetam principalmente crianças e idosos. E a exposição crônica ao material particulado fino, emitidos por combustíveis fósseis, sobretudo aqueles que contêm chumbo, aumenta o risco de doenças cardíacas e respiratórias, podendo evoluir, inclusive, para o câncer de pulmão. 0 aumento da poluição do ar em grandes centros urbanos tem sido associado ainda a todos os fatores de risco para doenças cardiovasculares, tais como a arritmia cardíaca, vasoconstrição e aumento da pressão arterial, isquemias do miocárdio e cerebral, progressão da arteriosclerose, entre outros (Cançado et al., 2006).

Em estudo realizado na Europa (Cançado et al., 2006), foram encontradas também evidências de associação entre mortalidade por doenças respiratórias e cardiovasculares com a aproximação do local da moradia à vias de grande fluxo de veículos. Tal evidência, se aplicada à cidade do Rio de Janeiro, pode demonstrar associação indireta ao poder aquisitivo da população. Quanto maior a pobreza, mais próxima a residência estará das vias de grande fluxo de veículos, tais como a Avenida Brasil e as Linhas Vermelha e Amarela. E, quanto mais próximas estiverem as residências de vias 
Figura 1 - Emissões de GEE do setor de Energia por subsetor (Gg CO2eq)

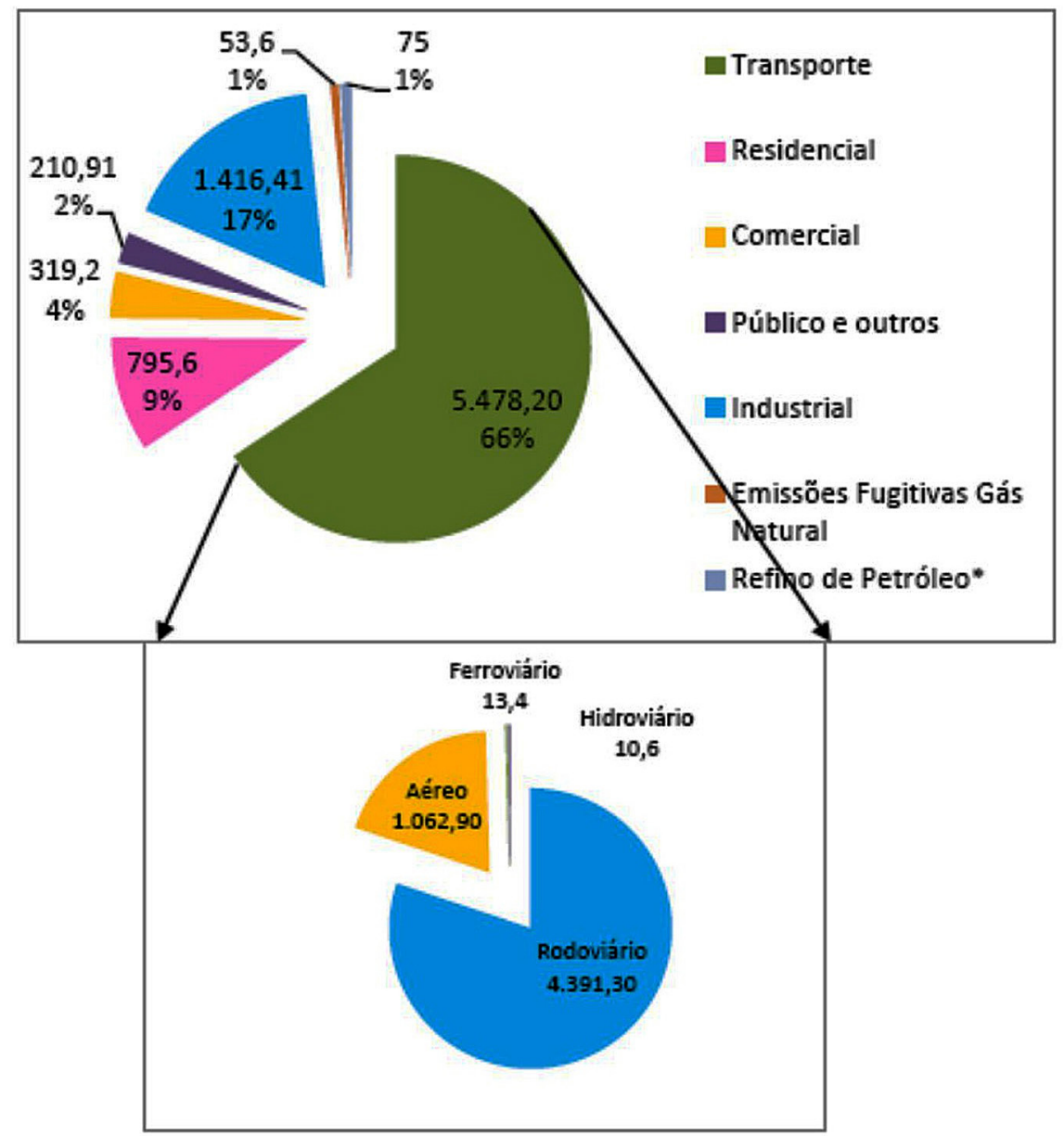

Fonte: Centro Clima/Coppe/UFRJ.

como essas, maior será o risco de indivíduos desse segmento da população morrerem por essas doenças.

0 chumbo é também um contaminante que traz prejuízos à saúde dos habitantes de centros urbanos poluídos. A presença de chumbo, apesar de ter sido reduzida na gasolina nos últimos anos, ainda persiste em alguns combustíveis. Segundo documento produzido pelo
Banco Mundial para a gestão da qualidade do ar em centros urbanos, a exposição ao chumbo contribui para problemas de comportamento e dificuldade de aprendizado em crianças urbanas (World Bank, 2000). A absorção de chumbo pelo organismo humano depende de fatores como a rota de exposição (inalação ou ingestão), forma química, tamanho da partícula e solubilidade dos compostos desse metal 
(Moreira e Moreira, 2004). E, caso a rota de exposição seja por inalação de gases de exaustão de motores, a absorção pode ser superior a $50 \%$, principalmente em indivíduos fumantes ou que sofram de doenças das vias respiratórias superiores.

Segundo Moreira e Moreira (2004), a presença de chumbo no organismo atinge os ossos, sangue, rins, medula óssea, fígado e cérebro, mas os efeitos biológicos adversos são observados principalmente no sistema nervoso, quando são considerados efeitos tóxicos críticos. Ainda segundo esses autores, os fatores nutricionais contribuem para o grau de absorção desse metal pelo organismo. $A$ alimentação precária e a deficiência de nutrientes, como cálcio, ferro, fósforo e proteínas, aumentam a absorção de chumbo pelo organismo. Portanto, mais uma vez é possível observar que as camadas mais pobres da população são as mais atingidas também por essa contaminação.

Fatores climáticos, como temperatura e umidade, também podem influenciar na qualidade do ar de uma cidade. No caso da cidade do Rio de Janeiro, a própria configuração fisiográfica, formada pelo relevo montanhoso e as baixadas, associados à presença da floresta e a proximidade com o mar constituem uma situação climática singular (Brandão, 2001). Tais elementos influenciam o sistema de ventos que varre a cidade. Contudo, o crescimento urbano e a distribuição de edificações alteram significativamente a direção e a intensidade desses ventos. Desse modo, é possível observar áreas com características climáticas diferentes no município do Rio de Janeiro. Segundo Serra e Ratisbona (in Brandão, 2001), as condições climáticas de áreas como a Zona Norte da cidade do Rio de Janeiro indicam níveis de umidade do ar inferiores aos da Zona Sul, não só pela menor influência da brisa marinha, como também porque essas áreas se encontram quase totalmente edificadas, assim há menor possibilidade de dispersão e uma tendência à maior concentração de poluentes nessas áreas.

Segundo Brandão (2001), o intenso processo de urbanização influencia diretamente para a concentração de calor nos grandes centros urbanos, conhecida como as "ilhas de calor". Isso faz as áreas urbanas alcançarem temperaturas mais altas do que seus arredores. 0 aumento da temperatura agrava a poluição do ar e gera zonas de baixa pressão, que contribuem para o aumento de chuvas nas áreas urbanas. E a ocorrência de chuvas nessas áreas, por sua vez, contribui para agravar os engarrafamentos, que aumentam a emissão e a concentração de poluentes, formando, assim, uma sequência de problemas interligados.

\section{Efeitos adversos na saúde causados pelo ruído e a vibração}

Outros efeitos associados ao fluxo intenso de veículos em áreas urbanas são o ruído e a vibração. Tais efeitos atingem a saúde da população, causando prejuízos à sua qualidade de vida. 0 ruído causado pelo tráfego urbano pode ocasionar problemas cardiovasculares, hormonais e estresse (Maciel et al., 2009). Segundo Pimentel-Souza (1993), o ruído de até 50dB pode incomodar, mas é passível de adaptação. A partir de $55 \mathrm{~dB}$ pode causar estresse e desconforto, mas a partir de $65 \mathrm{~dB}$ começam a ocorrer desequilíbrios bioquímicos no organismo, 
aumentando o risco de infarte, derrame cerebral, osteosporose, infecções, entre outros. $\mathrm{E}$ Magrini (1995) alerta: a partir de $85 \mathrm{~dB}$ podem ocorrer danos ao aparelho auditivo humano. A Organização Mundial de Saúde recomenda o limite de $70 \mathrm{~dB}$ para os ruídos das metrópoles, caso contrário serão escassas as possibilidades de um morador de uma grande cidade atingir a terceira idade com a sua audição preservada (Magrini, 1995).

Os efeitos do ruído na saúde humana podem ser bem mais graves quando a exposição ocorre durante o sono. 0 ruído compromete a qualidade do sono, o que prejudica a recuperação física e mental do corpo, causando o aumento da pressão sanguínea e da atividade cardíaca, bem como dificuldade de concentração e alterações respiratórias (Maciel et al., 2009). Segundo Pimentel-Souza (1993), os déficits de sono são cumulativos, causando o envelhecimento precoce e danos fisiológico, psicológico e intelectual. Os danos à qualidade do sono, causados pelo ruído podem não ser percebidos imediatamente, sendo notados somente quando a saúde do indivíduo já está comprometida (Pimentel-Souza, 1993).

Por tanto, toda a população moradora de grandes centros urbanos terá a sua saúde atingida pela poluição sonora causada pelo tráfego urbano, sobretudo os moradores de vias de grande fluxo de veículos. E, esses terão ainda outros problemas, ocasionados pelas vibrações provocadas pelo tráfego pesado sobre as edificações, causando efeitos fisiológicos diretos ou indiretos em seus moradores. Quanto maior for o porte da edificação, menor será a frequência em que ela irá vibrar. Contudo, a exposição a vibrações de baixa frequência é potencialmente mais perigosa do que a de altas frequências (Sebastião et al., 2007). E os efeitos fisiológicos diretos dessa exposição são náuseas, fadiga e tonteiras; enquanto os efeitos indiretos são dificuldade para dormir, dor de cabeça, mal-estar, perda de apetite e irritabilidade (Barceló, 2003).

\section{Considerações finais}

Diante de um dos problemas mais discutidos atualmente sobre as cidades, e mesmo opondo-se às premissas e diretrizes das políticas nacionais para o desenvolvimento urbano, torna-se fundamental a discussão da mobilidade urbana para reverter o caos que se tornou 0 espaço urbano e as suas consequências sobre a saúde da população.

Para embasar a seleção de medidas, é necessário serem seguidos os princípios de mobilidade urbana sustentável, indicados por referências federais - como o Caderno de Referência para Elaboração de Plano de Mobilidade Urbana (PlanMob), o Estatuto da Mobilidade, a Política Nacional de Mobilidade Urbana Sustentável - e parâmetros acadêmicos - como os Indicadores de Mobilidade Urbana Sustentável e condicionantes de Nível de Serviço de modos não motorizados.

Sendo assim, há a necessidade de rever as prioridades das cidades: incentivar caminhadas; diminuir a largura de cruzamentos para dar maior segurança aos pedestres; criar maior número de atividades de lazer em espaços públicos; desenhar maior número de ciclofaixas e ciclovias; uso de corredores de grande capacidade com linhas exclusivas para 
transporte público; controlar o uso de veículos privados e incentivo ao compartilhamento dos automóveis; limitar estacionamentos; incentivar o uso de veículos de entrega mais limpos, silenciosos, menores e com baixa velocidade; uso misto do solo urbano (residencial, comercial e de trabalho) com maior densidade e compactação; descobrir o ambiente natural e as tradições étnicas; criar redes densas de ruas e passagem para pedestres e bicicletas e projetar ruas e espaços públicos com maior qualidade construtiva, tendo maior preocupação com sua gerência e conservação.

As discussões sobre o tema viário tiveram início numa época em que a abertura de avenidas e autoestradas aconteceu antes mesmo da presença irremediável do automóvel, mostrando o quanto os técnicos que estudavam a cidade estavam à frente de seu tempo, fossem eles sanitaristas, engenheiros, arquitetos ou urbanistas. Procuramos colocar em discussão o quanto a modernização das cidades não tardaria a torná-las reféns dos automóveis, aí incluindo caminhões e carros de passeio. Aprendemos que, na verdade, acreditava-se na grande salvação das cidades pelo veículo automotor. Muito se fala, também, na atualidade, sobre a má conservação das nossas rodovias e o quanto o Estado tem sido especialmente negligente sobre o assunto, quando este foi responsável pela bem-sucedida carreira de alguns políticos, especialmente Washington Luís e Getúlio Vargas.

0 uso excessivo de automóveis em detrimento a outros meios de transporte nas grandes cidades tem se mostrado insustentável e ineficaz, visto que representam a maior fonte de emissão de gases do efeito estufa em áreas urbanas e, sobretudo, não resolvem a questão da mobilidade nessas áreas. 0 incentivo ao uso de meios de transportes menos poluentes e com maior capacidade de passageiros deverá ser a prioridade das administrações públicas nos próximos anos, principalmente na cidade do Rio de Janeiro que irá sediar a Copa, em 2014, e as Olimpíadas em 2016.

Nosso estudo espera, dentro da linha da recente história urbana carioca e brasileira, contribuir para que se compreenda como o planejamento urbano - ou a falta dele - levou a fazer dos eixos rodoviários um dos emblemas da vida moderna e o quão influentes eles podem ser para a qualidade de vida e a saúde nas cidades. 


\section{Renato Gama-Rosa Costa}

Fundação Oswaldo Cruz, Escola Nacional de Saúde Pública Sergio/Fiocruz. Rio de Janeiro/RJ, Brasil. rgrc@fiocruz.br

\section{Claudia G. Thaumaturgo da Silva}

Fundação Oswaldo Cruz, Escola Nacional de Saúde Pública Sergio Arouca. Rio de Janeiro/RJ, Brasil. thauma@ensp.fiocruz.br

\section{Simone Cynamon Cohen}

Fundação Oswaldo Cruz, Escola Nacional de Saúde Pública Sergio Arouca. Rio de Janeiro/RJ, Brasil. cohen@ensp.fiocruz.br

\section{Referências}

BARCELÓ, C. (2003). "Fatores físicos de risco à saúde na habitação e seu entorno". Curso realizado na Escola Nacional de Saúde Pública/Fiocruz em parceria com o Cepis/OPS-OMS (Centro Pan-Americano de Engenharia Sanitária e Ciências do Ambiente) em abril de 2003. Documentos técnicos disponíveis em: http://www.cepis.ops-oms.org, na área Salud en la vivienda. Acesso em: 5/4/2012.

BARLES, S. e GUILLERME, A. (2003). Traffic congestion: Problems and solutions in Paris, 1830-1939. In: T2M CONFERENCE. Anais. Eindhoven, Holanda.

BENETTI, P. (1997). Projetos de avenidas no Rio de Janeiro (1880-1995). Tese de doutorado. São Paulo, Universidade de São Paulo.

BRANDÃO, A. M. P. M. (2001). "Clima Urbano e Enchentes na Cidade do Rio de Janeiro". In: GUERRA, A. J. T. e CUNHA, S. B. (orgs.). Impactos Ambientais Urbanos no Brasil. Rio de Janeiro, Bertrand Brasil, pp. 47-109.

BUSS, P. M. e PELLEGRINI FILHO, A. (2007). A saúde e seus determinantes sociais. Physis. Rio de Janeiro, v. 17, n. 1, pp. 77-93.

CAIAFFA, W. T. et al. (2008). Saúde urbana: "a cidade é uma estranha senhora, que hoje sorri e amanhã te devora". Cien. Saude Col. Rio de Janeiro, v. 13, n. 6.

CANÇADO, J. E. D; BRAGA, A.; PEREIRA, L. A. A.; ARBEX, M. A.; SALDIVA, P. H. N. e SANTOS, U. P. (2006). Repercussões Clínicas da Exposição à Poluição Atmosférica. Jornal Brasileiro de Pneumologia, v. 32, suppl. 2., pp. 5-11, São Paulo.

CENTRO CLIMA (2011). Inventário e cenário de emissões dos gases de efeito estufa da cidade do Rio de Janeiro. Centro Clima/Coppe/UFRJ. Disponível em: www.centroclima.org.br. Acesso em: 24/4/2012. 
COSTA, R. G.-R. (2006). Entre "Avenida" e "Rodovia": a história da Avenida Brasil (1906-1954). Tese de doutorado. Rio de Janeiro, Universidade Federal do Rio de Janeiro.

DINHOBL, G. (2003). Cultural narratives. A History of transport history. In: T2M CONFERENCE. Anais. Eindhoven, Holanda.

DUPUY, G. (1991). L'Urbanisme des réseaux. Théories et méthodes. Paris, Armand Colin.

ENCYCLOPEDIE D'HYGIENE ET DE MEDICINE PUBLIQUE (1897). Livre III - Hygène Urbaine. Chapitre II - La Voie Publique. Paris.

FLONNEAU, M. (2003a). Facing the explosion of mobility in the parisian area - the socalled "exclusive car-oriented policy" in Paris 1960-1970. In: T2M CONFERENCE. Anais. Eindhoven, Holanda.

(2003b). L'action optimiste et raisonnée du District de la région parisienne: l'exemple des "dix glorieuses de l'urbanisme automobile" 1963-1973. In: T2M CONFERENCE. Anais. Eindhoven, Holanda.

HALL, S. (org.) (1997). Representation. Cultural representation and cultural signifying practices. London/Thousand Oaks/New Delhi, Sage/Open University.

HÉNARD, E. (1982). Études sur les Transformations de Paris. 1909. Paris, L'Equerre. Edição fac-simile. IPEA (2011). SIPS - Sistema de Indicadores de Percepção Social - Mobilidade Urbana. Brasília, IPEA.

KLEIMMAN, M. (1994). De Getúlio a Lacerda: um "rio de obras" transforma a cidade do Rio de Janeiro. As obras públicas de infraestrutura urbana na construção do "Novo Rio" no período de 19381965. Tese de doutorado. São Paulo, Universidade de São Paulo.

LE CORBUSIER (2000). Urbanismo. 1925. São Paulo, Martins Fontes.

MACIEL, B. A.; RIBEIRO, R. J. C.; BIAS, E. S.; GARAVELLI, S. L. e CAVALCANTI, M. M. (2009). Modelagem do Ruído Urbano como Instrumento de Gestão Ambiental. In: XIV SIMPÓSIO BRASILEIRO DE SENSORIAMENTO REMOTO. Anais. Natal-RN, de 25 a 30 de abril.

MACSHANE, C. (1984). De la rue à I'autoroute. 1900-1940. Les Annales de la Recherche Urbaine, Paris, n. 23-24, pp. 17-18.

MAGRINI, R. J. (1995). Poluição sonora e Lei do Silêncio. Revista Jurídica, n. 216, p. 20.

MOREIRA, J. C. e MOREIRA, F. R. (2004). A importância da especiação do chumbo em plasma para a avaliação dos riscos à saúde. Revista Química Nova, v. 27, n. 2, pp. 251-260.

ORGANIZAÇÃO PAN-AMERICANA DA SAÚDE (2007). Primer Foro Regional de Salud Urbana. Caminando hacia um marco conceptual de salud urbana y agenda para la acción en las Américas. La iniciativa de la OPS: Foro de Salud Pública de las Américas. Ciudad de México: 27-29 de noviembre.

PIMENTEL-SOUZA, F. (1992). Efeitos da poluição sonora no sono e na saúde em geral - Ênfase urbana. Revista Brasileira de Acústica e Vibrações, ed. 10, pp. 1-5.

(1993). Os riscos ao sono: uma avaliação dos efeitos da poluição sonora urbana no trabalho e na saúde. Revista Proteção, v. 5, n. 23, pp. 32-38.

SEBASTIÃO, A. B.; MARZIALE, M. H. P. e ROBAZZI, M. L. C. C. (2007). Uma revisão sobre efeitos adversos ocasionados na saúde de trabalhadores expostos à vibração. Revista Baiana de Saúde Pública, v. 31, n. 1, pp. 178-186. 
SORIA y MATA, A. (1882/1913). La Cité Lineaire: nouvelle archicteure de villes. Madrid, Imprenta de la ciudad lineal.

WIRTH, L. (1987). “O urbanismo como modo de vida”. In: VELHO, O. G. (org.). O fenômeno urbano. Rio de Janeiro, Zahar.

WORLD BANK (2000). Urban Air Quality Management - The Transport-Environment-Energy Nexus. Washington D.C.

Texto recebido em 5/ago/2012

Texto aprovado em 25/set/2012 
